\title{
Prendas de un idioma CREPuscular: Versión ORIginal DEl PREFACIO de Altazor de Vicente Huidobro
}

\author{
Mario Nandayapa
}

A

lgo me toca el hombro. Me estremece un fino y tenso temblor, cuando estoy frente a frente de un indiscutible mito literario, construyendo una saga en mi vida a partir de este suceso: tener acceso al manuscrito original de Altazor de Vicente Huidobro, ver su caligrafía, ser cómplice de lo que es, medir el peso, sentir el tiempo y el arte en estas mínimas manos que se avergüenzan de mi conformación.

Tuve a bien contar con el apoyo de La Fundación Vicente Huidobro, donde me dieron la oportunidad de fotografiar el manuscrito del Prefacio de Altazor. Esta Fundación se constituyó en 1990 con el fin de preservar el legado del poeta, una de las más altas y originales figuras literarias chilenas y de las letras castellanas del siglo pasado; y de mantener ese legado en Chile, acrecentarlo, organizarlo y ponerlo en valor de tal manera que cumpla un fin cultural y social significativo, difundiendo su obra y fomentando la creatividad de la sociedad. Para esos fines creó un Centro de Documentación y Archivo donde se resguarda el conjunto de manuscritos, epistolario, piezas fotográficas, primeras ediciones, y documentos de diversa naturaleza (diarios, revistas, documentos de

Mario Nandayapa, Facultad de Humanidades de la UNACH. Actualmente cursa el Programa de Doctorado en Literatura en la Universidad de Chile. época) que conforman el legado de Vicente Huidobro, y constituyen el patrimonio artístico de la Fundación.

El presente texto, escrito para la revista Liminar. Estudios sociales y bumanísticos del Centro de Estudios Superiores de México y Centroamérica, tiene el propósito de difundir entre la población chiapaneca la obra del poeta chileno Vicente Huidobro. Está diseñado en tres apartados, el primero da cuenta de un análisis del Prefacio de Altazor, el siguiente está constituido de 18 imágenes del manuscrito original; y el último apartado es la reproducción de la versión final, y la que se conoce, del Prefacio de Altazor.

\section{Introducción}

Altazor es considerado el poema más importante de Vicente Huidobro y uno de los hitos de la poesía escrita en lengua española. Este libro fue publicado en el año 1931 en Madrid España, sin embargo, no existe una absoluta certeza acerca de la fecha en que se comenzó a escribir. Tradicionalmente se ha sostenido que Altazor habría sido iniciado en 1919, no obstante en el manuscrito nos encontramos con la siguiente nota introductoria: 
En realidad este poema fue empezado en 1918 a [ilegible] raíz de la publicación de Ecuatorial (Madrid, Julio 1918) pero entonces sólo escribí el Prefacio y el Primer Canto. Todo el resto en Chile fue escrito en 1919 y corregido en 1920. En octubre de 1919, Cansinos Assens habló de él en la "Correspondencia de España”. Equivocadamente dio a todo el poema el título del prefacio "Altazor o El viaje en paracaídas.

De esta manera se pone en conflicto la fecha que tradicionalmente se consideraba de inicio. Relacionado con lo anterior, en el manuscrito del poema encontramos destacada la fecha de 1919 con el objeto de hacernos creer que fue iniciado y completado en esa fecha. Frente a las dudas sobre este tema, se puede afirmar con seguridad que el poema fue terminado después de 1920.

Los hechos que acabamos de mencionar, más allá de que sean verdaderos o no, pueden entenderse como manifestación de la obsesiva "voluntad inaugural" del autor, este deseo de ser el primero, el más avanzado en la literatura, rasgo característico de las vanguardias. Se añade a lo anterior que en un primer momento $A$ ltazor comenzó a escribirse en francés. Sin embargo, el autor, al comprender lo inédita que sería su obra en la lengua española, decidió cambiarla a esta lengua.

La palabra Altazor es un neologismo que puede descomponerse en dos elementos: alto: adjetivo, que nos sitúa desde un plano aéreo, cósmico; y azor: ave de presa. Esta ave es evocada desde temprano en la poesía española. Se puede encontrar en el poema del Cid y en el Romancero Viejo. En el Cid, el azor es símbolo de cuánto ha de abandonar en el destierro y de lo valioso como el Condado de Castilla. Huidobro, buen conocedor de las letras españolas y particularmente interesado en la épica y el romancero, dará a esta ave una categoría superior. Altazor era quien veía más allá de lo que veía el resto de los hombres.

Los subtítulos de Altazor son también muy significativos. El primero, "El pasajero de su destino", nos entrega una palabra clave: pasajero. El pasajero nos hace referencia a un viaje, movimiento, y a la vez denota, como adjetivo, cambio, fluidez, nada es constante ni duradero. La palabra destino bien podría referirse a uno de los temas centrales de este poema: la muerte, como paradero inevitable.

El segundo subtítulo hace más explícita esta cualidad de movimiento y fluidez con la palabra Viaje. El paracaídas, que es el objeto que guía este viaje, no es otra cosa que la poesía (es decir, lo que Huidobro entiende por poesía) y lo es porque suspende y deja ver, como dice Federico Schopf. En efecto, Altazor es viaje y a la vez caída.

Este poema, está inscrito en el movimiento vanguardista denominado Creacionismo, del cual Huidobro será fundador y mayor exponente. Su nombre alude al verbo fundamental para esta vanguardia: crear. El poeta es un pequeño dios, creador de un mundo aparte de la realidad, no obstante, toma elementos de la realidad objetiva pero a través de las nuevas relaciones que establece entre ellos, crea algo nuevo: un mundo autónomo, con sus propias leyes. En este sentido, el poeta se rebela contra la naturaleza, pero mejor dicho en contra de la tradicional obligación del artista de imitar la naturaleza (mimesis), como única función del arte. Huidobro le dice a la naturaleza non serviam, no te serviré y haré como tú: crearé.

\section{Una relectura al prefacio de Altazor}

El Prefacio de Altazor pretende asumir una forma lineal y discursiva, haciendo uso de una retórica narrativa que se encamina hacia la expansión, y que incluye un héroe en tránsito. Estos elementos son, aparentemente, más que suficientes para inducir a una categorización convencional de un prefacio, sea por la forma que asumen, como por los contenidos que engloban. Pero una lectura atenta nos muestra que estamos en el campo de la trasgresión, y como tal, en el de la parodia. 
En este sentido, el Prefacio no se insurge apenas contra los modelos sobre los cuales se apoya (la autobiografía y la Biblia), sino que acaba parodiándose a sí mismo, constituyendo una especie de antiprefacio.

Las tensiones instauradas no provienen apenas de los aspectos del género contra los cuales se vuelca, sino que se producen dentro del propio discurso, al introducir elementos de cuño poético que hacen oscilar a todo momento el esqueleto de la narrativa; encontramos así una condensación metafórica acentuada y continua, así como un ritmo que se basa en la redundancia y la anáfora poética. Este balanceo de la prosa va más allá de la distensión formal provocada por el verso libre, remitiendo en consecuencia a la hibridación de los géneros.

Sin llegar a ser un prefacio propiamente dicho, sin ser una obra paródica por excelencia, sin ser prosa ni verso, el Prefacio de Altazor se abre como una serie de alternativas que, además de negarse a sí mismas, contienen en germen todos los núcleos de significación que van a desarrollarse en el transcurso de los siete Cantos.

\section{Génesis y parodia}

Desde el punto de vista formal, el prefacio desempeña una función iniciática notoria. Encontramos entonces, especularmente y a nivel temático, la narración del inicio, la constitución de la historia, el pasaje del caos al cosmos mediatizado por la palabra; en resumen, la organización de y por el lenguaje. Concomitante al inicio la crítica de la palabra como perspectiva moderna de lo simultáneo. $\mathrm{Al}$ mismo tiempo en que se crea, se critica: creación y crítica, lenguaje y metalenguaje, texto y metatexto, inicio y vuelta sobre sí mismo, génesis y parodia.

\section{El modelo autobiográfico}

Un primer nivel de esta introducción genésica buscará apoyo en el modelo autobiográfico. Así, el texto tiene inicio con el convencional Nací, que debería dar secuencia a la determinación del año y lugar de nacimiento; la narración realiza este proyecto autobiográfico, pero a nivel poético y metafórico rompe con el modelo que le sirve como punto de partida. De este modo, especifica el poeta: Nací a los treinta y tres años, el día de la muerte de Cristo; nacien el Equinoccio, bajo las hortensias y los aeroplanos del calor.

La trasgresión del modelo autobiográfico es notoria; el nacimiento aparece transfigurado en operación metafórica, dando lugar a un texto antibiográfico, donde el héroe se configura como un punto de intersección: surge para establecer dialécticamente una continuidad y una oposición a Cristo: un anti-Cristo. Espejea de este modo, y a nivel temático, el proceso formal que utiliza la autobiografía tradicional, pero para subvertirla; así, Cristo es necesario como regla para poder provocar el desvío paródico. Este punto intermediario, que quedó establecido a nivel temporal, se proyecta en el espacio: naci en el Equinoccio, determinando espacialmente un diseño de la órbita de la Tierra en que se igualan el día y la noche.

La propuesta de una narrativa autobiográfica tiene continuidad al insistir con modelos cristalizados por el género: así, tiene secuencia una tentativa convencional de descripción: Mipadre y Mi madre, y nuevamente, la expresión metafórica, sirve como artefacto parodiante y destructor del referente cero: Mi padre era ciego y sus manos eran más admirables que la noche (...) Mi madre bablaba como la auroray como los dirigibles que van a caer.

\section{E1 referente bíblico}

El segundo nivel parodiante tiene a la Biblia como referente parodiado; específicamente el texto de la creación del mundo: el Génesis original: Entonces oí hablar al Creador, sin nombre, que es un simple hueco en el vacio, hermoso como un ombligo. 
Nuevamente, el Caos (ausencia de forma), es descrito metafóricamente: un simple hueco en el vació, sugiriendo una imagen espacial de la nada dentro de la nada. La necesidad de describirlo es decurrente de la ausencia de su nombre, que toma necesaria una calificación atributiva para aproximarnos a su definición. Si al inicio fue el Verbo, que transformado en palabra escrita genera el Génesis bíblico, contamos aquí con un Creador, sin nombre, transfigurado en discurso poético. Y tiene inicio Altazor el mito de la creación: Hice un gran ruido y este ruido formó el océano y las olas del océano.

Así como la palabra, el código sonoro (ruido) es el instrumento que organiza el universo, en última instancia el texto. La parodia surge en la propia organización de la narrativa, pues el relato original se realiza en el discurso indirecto y aquí nos encontramos con el discurso directo y compartimos junto con Altazorla recepción del mensaje, siendo que él se nos antepone: oi hablar al Creador. La parodia es evidente en el efecto de reducción que el discurso sufre a través de la comparación: Este ruido irá siempre pegado a las olas del mar y las olas del mar irán pegadas a él, como los sellos en las tarjetas postales.

La eventual grandiosidad del gesto divino de la creación de las aguas, y el aspecto sonoro de las olas, se oblitera con la trivialización de la comparación. Esta inversión total, que lleva a tratar lo sagrado como profano, es un rasgo típico de una escritura que trata de quebrar las expectativas condicionadas del lector. Del mismo modo, el tono irreverente y humorístico del discurso divino: Después bebi un poco de coñac (a causa de la bidrografía).

Y finalmente la última y más importante etapa de la creación: Creéla lengua de la boca que los hombres desviaron de su rol, baciéndola aprender a hablar..., a ella, ella, la bella nadadora, desviada para siempre de su rol acuático y puramente acariciador.

Es el nacimiento de la palabra, a la cual ya se le atribuye función poética. El poeta le retira a la lengua los condicionamientos automatizados su rol acuático y puramente acariciador y la convierte en lenguaje. Pero este lenguaje ya se anuncia como lenguaje figurado: primero en la insistencia sobre el carácter de desvío del mismo, y en segundo lugar la actualización del relato, en el uso metafórico realizado por el propio poeta-demiurgo: ella [la lengua] la bella nadadora.

\section{La génesis verbal}

Aún dentro de la propuesta genésico-paródica del Prefacio, destacamos un tercer nivel, que remite a la creación de la palabra: $Y$ aprovechando este reposo bien ganado, comencé a llenar con profundos pensamientos las casillas de mi tablero.

Encontramos en principio una elaboración metalingüística, pero en el sentido de una programática textual, de acuerdo con las propuestas de E. A. Poe (Philosophy of Composition), al identificar (metafóricamente) la organización de la palabra como distribución de la misma en las casillas de un tablero, según una serie de alternativas y probabilidades combinatorias (no estamos lejos de Un lance de dados de Mallarmé). Lo que crea el efecto paródico no es el modo como el lenguaje se define y se estructura, sino el hecho de volcarse directamente sobre la poesía narrativa anterior, que describe la creación del universo. Y empiezan a establecerse así las equivalencias: así como Dios crea el Universo a través de la palabra, el poeta define y hace nacer la poesía. Desde el punto de vista de la organización de la narrativa, el autor/yo lírico narra y describe en primera persona: Entonces oí hablar al Creador, para dar lugar inmediatamente después al discurso directo, con el uso deliberado de comillas. Paralelamente, el poeta anuncia sus pensamientos en el discurso indirecto, para posteriormente hacer también uso de comillas. Las analogías se extienden: los dos demiurgos usan siete oraciones (número mágico, cabalístico) para postular sus principios genésicos. Vemos entonces cómo productores y producto se igualan: Creador/poeta, Universo/poesía. Y aquí la parodia surge en segundo 
grado, pues el discurso del poeta se basa en el del Creador que, a su vez, usa el referente bíblico, convirtiéndose entonces en proyección abismal y simultánea de otros dos discursos: el bíblico y el del propio prefacio. Así como el efecto paródico se desdobla, también el metalenguaje, que se vuelca no apenas sobre un tipo de lenguaje, sino sobre dos: lenguaje de un lenguaje, creación de la creación, parodia de una parodia. Resumiendo, encontramos en el Prefacio tres niveles de escritura paródica, cuyos grados cero son respectivamente el texto autobiográfico, la Biblia y el Arte Poética.

\section{Fotografías del manuscrito del Prefacio de Altazor}

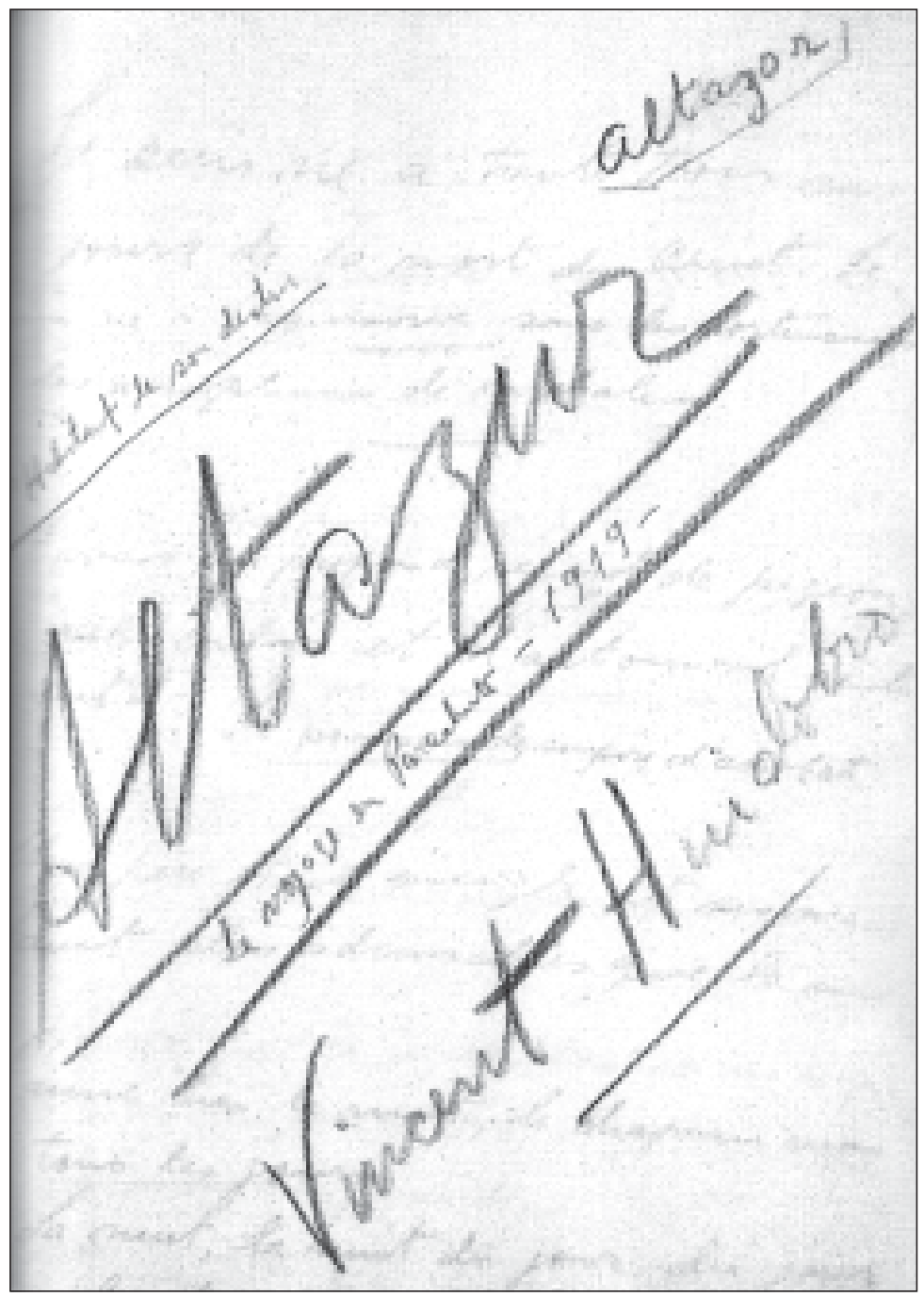



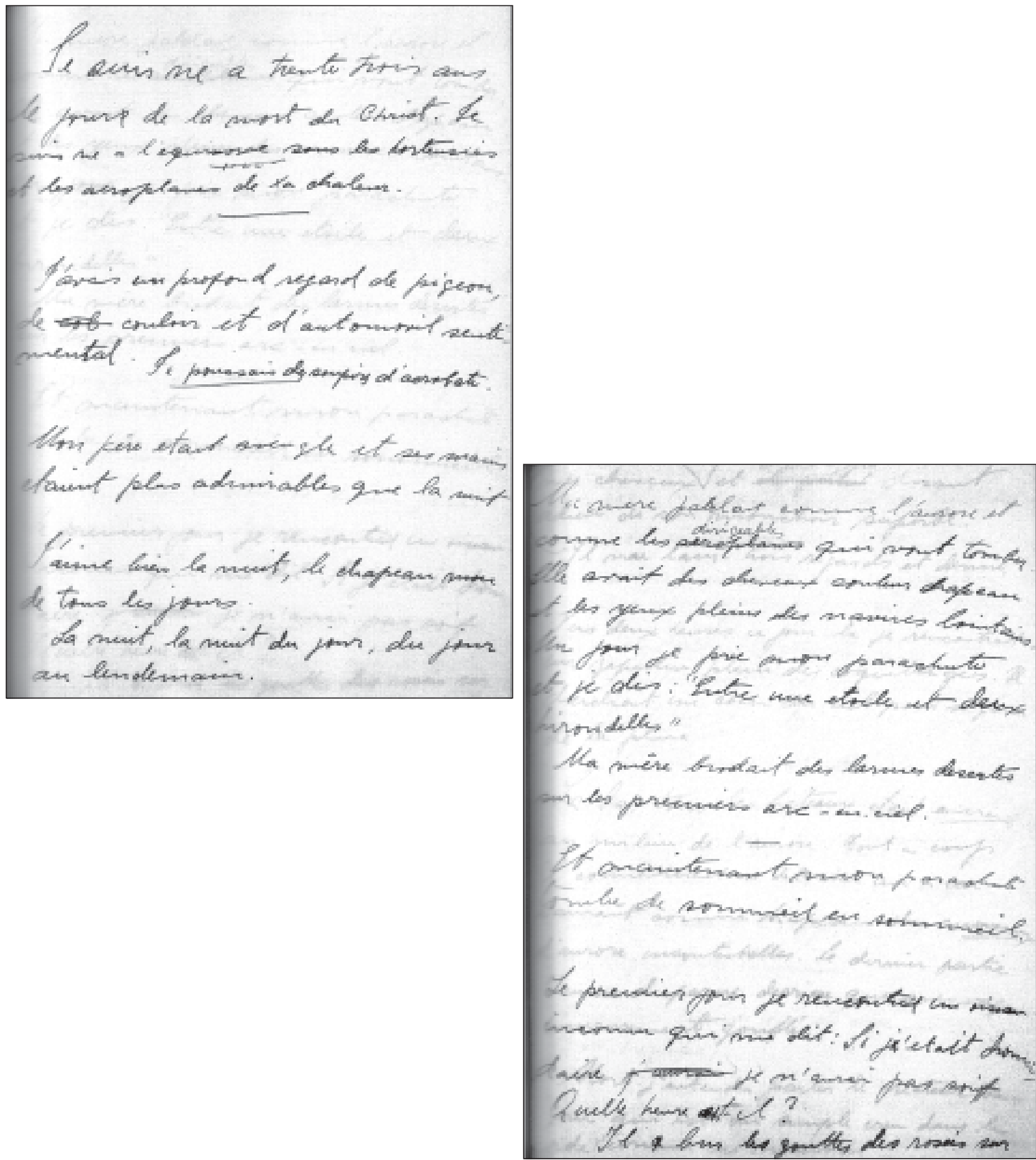

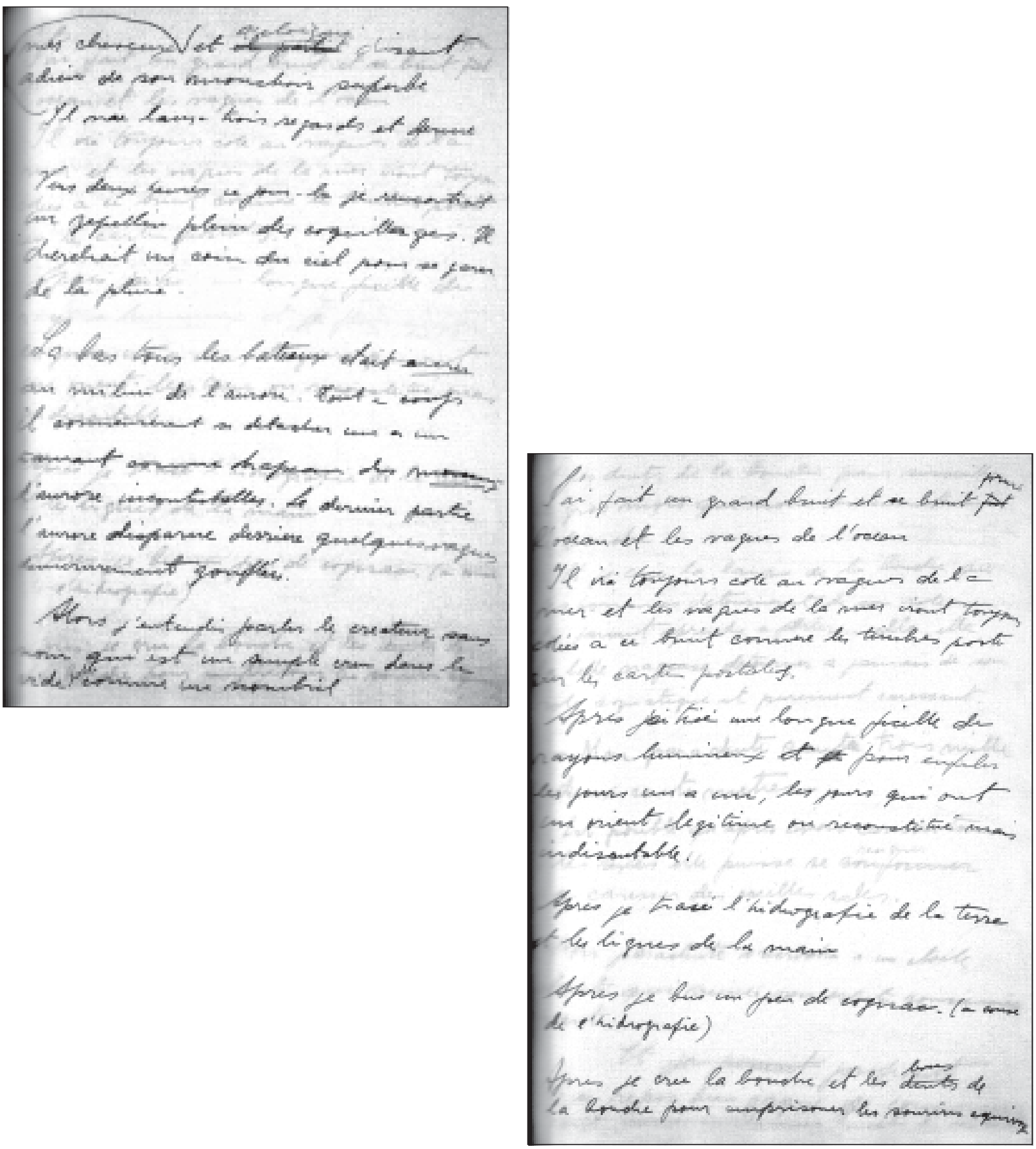

161 


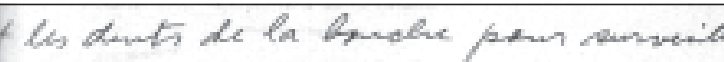
pro mots quimons diement. bonethe

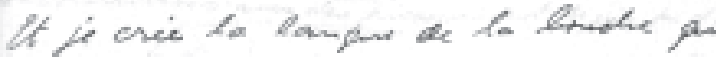
- hommes detromment de an whe

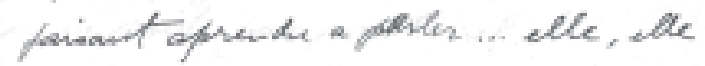

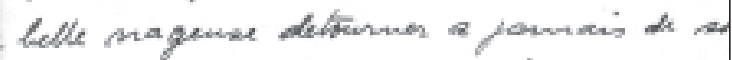

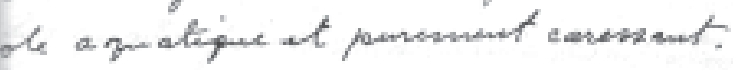
- Mor para dinte sautá tros mil denx cents metres-

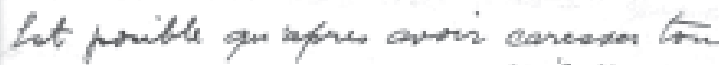

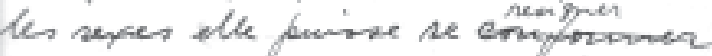
a casesan dies railles dates.

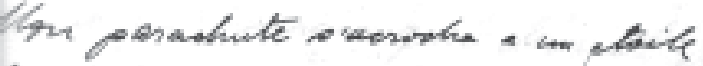

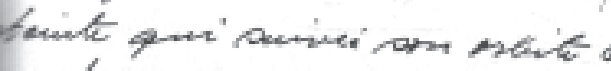
reant

\section{Lt te tremait}

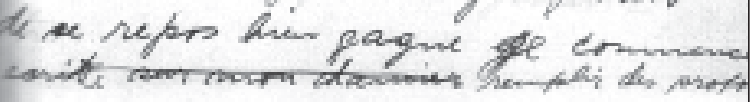

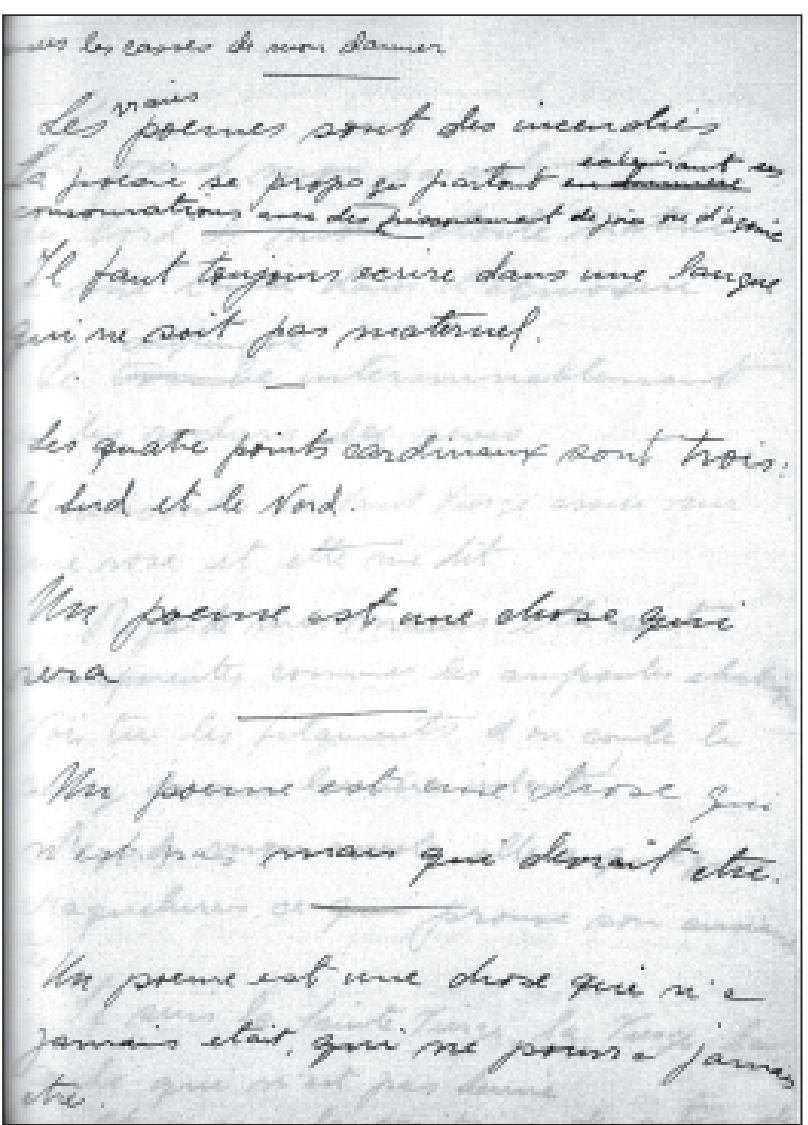



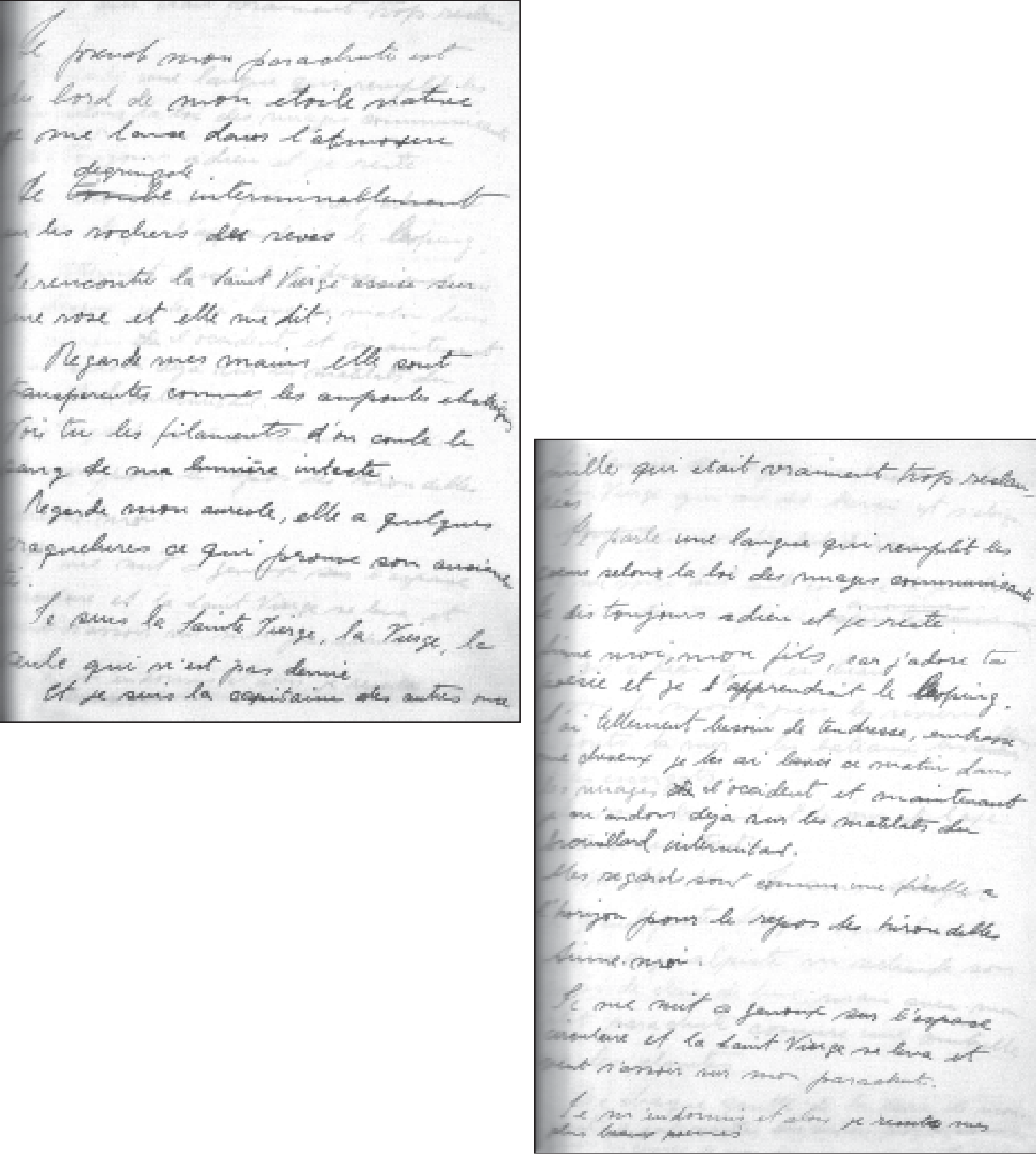

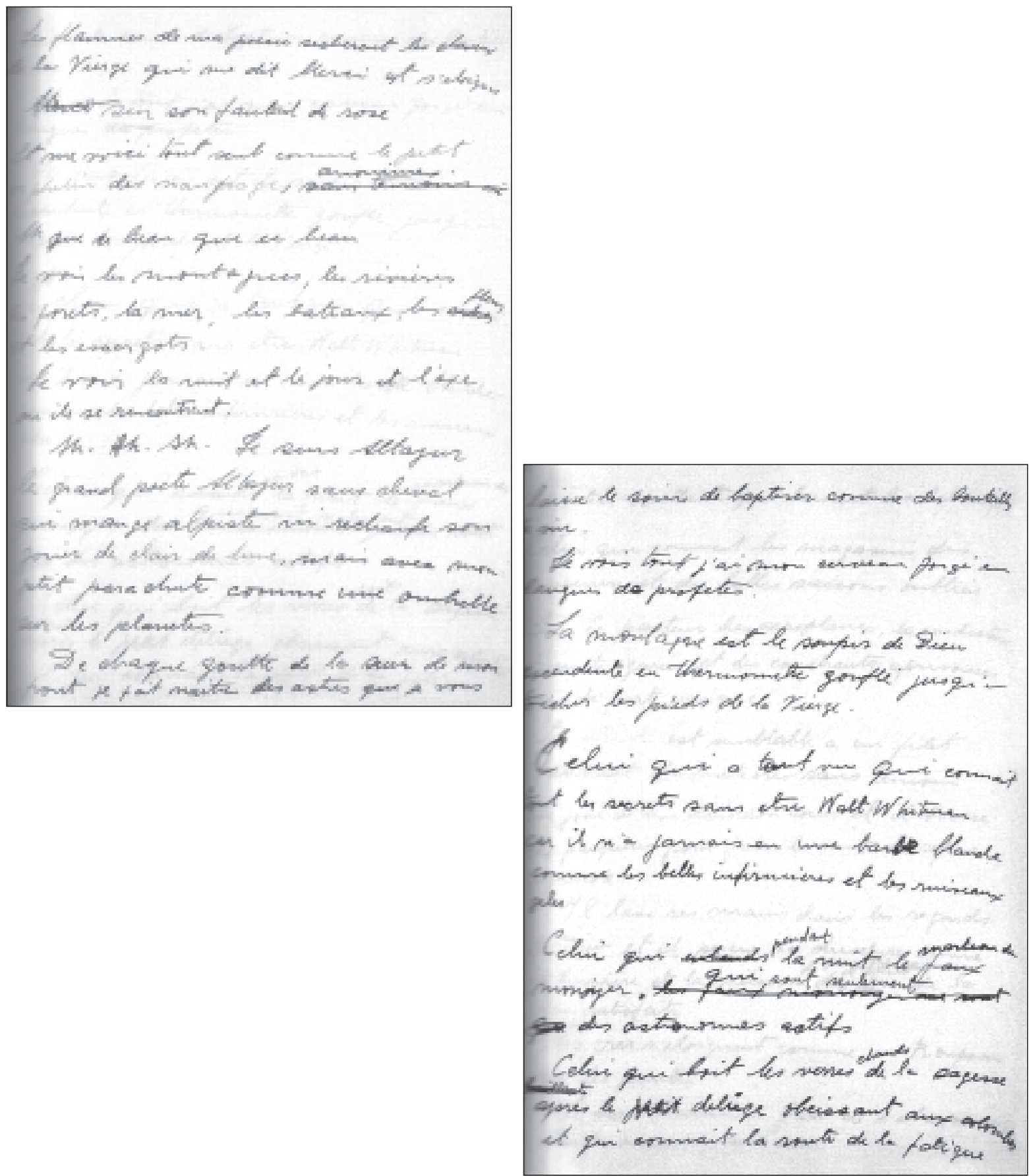


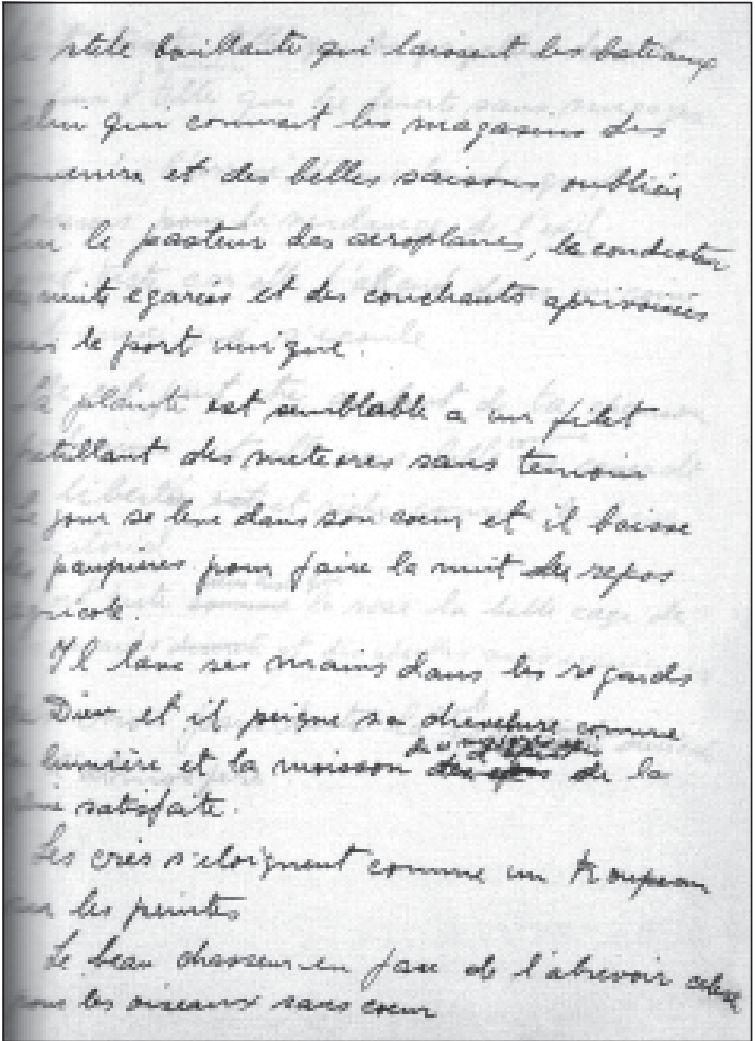
thise tell que to jayelle, derant

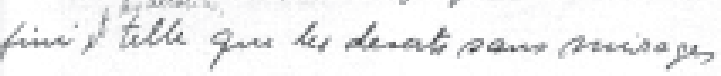

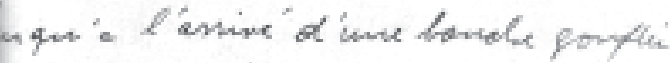

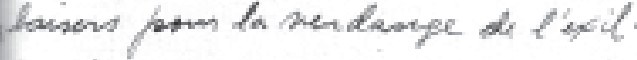

rit histe cor elle t attand dan un coin

l'amtí qué o'ecomle

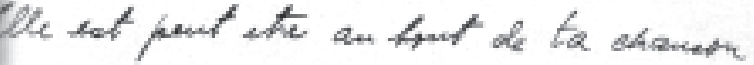

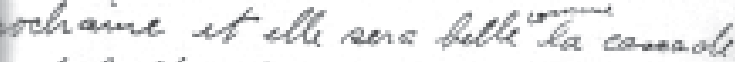

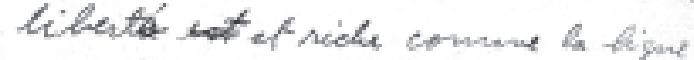
enatorial

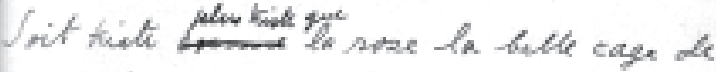

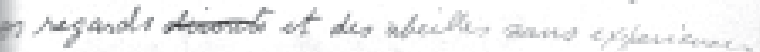

th omon parachute lawe l'atmospere. 

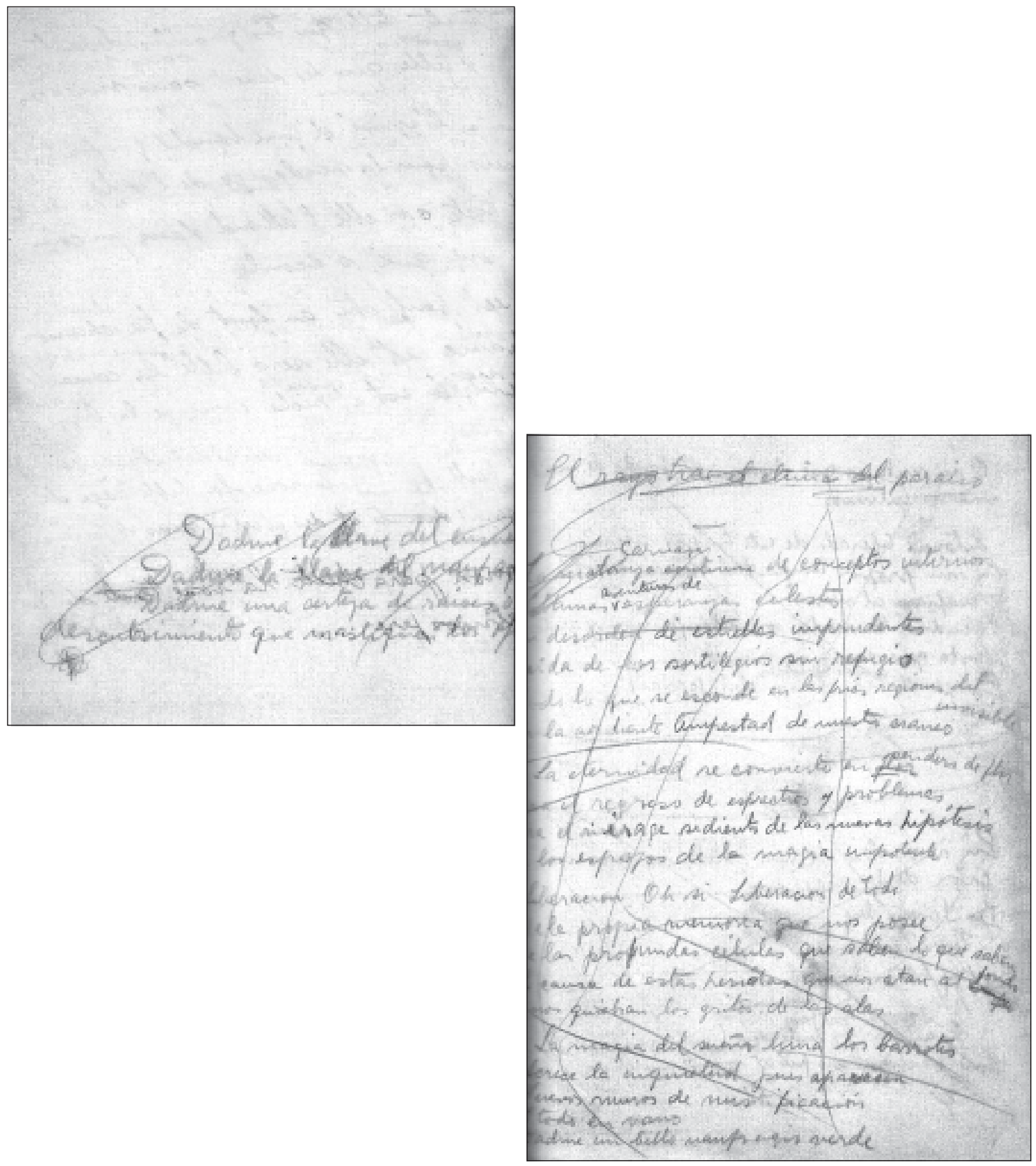
D O CUMENTOS
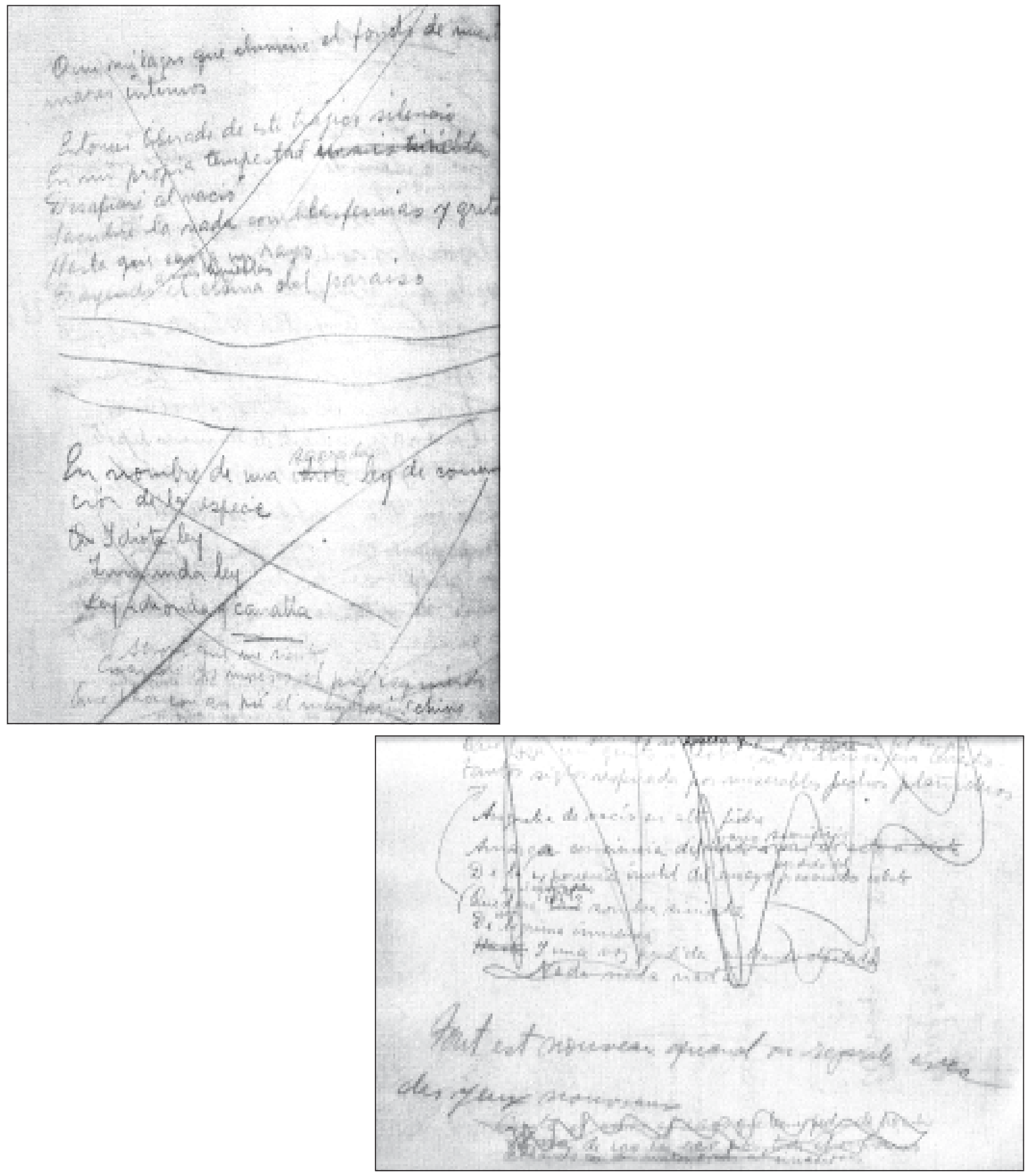

167 


\section{Versión final del Prefacio de Altazor (1930)}

Nací a los treinta y tres años, el día de la muerte de Cristo; nací en el Equinoccio, bajo las hortensias y los aeroplanos del calor.

Tenía yo un profundo mirar de pichón, de túnel y de automóvil sentimental. Lanzaba suspiros de acróbata.

Mi padre era ciego y sus manos eran más admirables que la noche.

Amo la noche, sombrero de todos los días.

La noche, la noche del día, del día al día siguiente.

Mi madre hablaba como la aurora y como los dirigibles que van a caer. Tenía cabellos color de bandera y ojos llenos de navíos lejanos.

Una tarde, cogí mi paracaídas y dije: «Entre una estrella y dos golondrinas". He aquí la muerte que se acerca como la tierra al globo que cae.

Mi madre bordaba lágrimas desiertas en los primeros arcoiris.

Yahora mi paracaídas cae de sueño en sueño por los espacios de la muerte.

El primer día encontré un pájaro desconocido que me dijo: "Si yo fuese dromedario no tendría sed. ¿Qué hora es?" Bebió las gotas de rocío de mis cabellos, me lanzó tres miradas y media y se alejó diciendo: "Adiós" con su pañuelo soberbio.

Hacia las dos aquel día, encontré un precioso aeroplano, lleno de escamas y caracoles. Buscaba un rincón del cielo donde guarecerse de la lluvia.

Allá lejos, todos los barcos anclados, en la tinta de la aurora. De pronto, comenzaron a desprenderse, uno a uno, arrastrando como pabellón jirones de aurora incontestable.

Junto con marcharse los últimos, la aurora desapareció tras algunas olas desmesuradamente infladas.

Entonces oí hablar al Creador, sin nombre, que es un simple hueco en el vacío, hermoso, como un ombligo.

Hice un gran ruido y este ruido formó el océano y las olas del océano.

Este ruido irá siempre pegado a las olas del mar y las olas del mar irán siempre pegadas a él, como los sellos en las tarjetas postales.
Después tejí un largo bramante de rayos luminosos para coser los días uno a uno; los días que tienen un oriente legítimo y reconstituido, pero indiscutible.

Después tracé la geografía de la tierra y las líneas de la mano.

Después bebí un poco de cognac (a causa de la hidrografía).

Después creé la boca y los labios de la boca, para aprisionar las sonrisas equívocas y los dientes de la boca, para vigilar las groserías que nos vienen a la boca.

Creé la lengua de la boca que los hombres desviaron de su rol, haciéndola aprender a hablar... a ella, ella, la bella nadadora, desviada para siempre de su rol acuático y puramente acariciador".

Mi paracaídas empezó a caer vertiginosamente. Tal es la fuerza de atracción de la muerte y del sepulcro abierto.

Podéis creerlo, la tumba tiene más poder que los ojos de la amada. La tumba abierta con todos sus imanes. Y esto te lo digo a ti, a ti que cuando sonríes haces pensar en el comienzo del mundo.

Mi paracaídas se enredó en una estrella apagada que seguía su órbita concienzudamente, como si ignorara la inutilidad de sus esfuerzos.

Yaprovechando este reposo bien ganado, comencé a llenar con profundos pensamientos las casillas de mi tablero:

Los verdaderos poemas son incendios. La poesía se propaga por todas partes, iluminando sus consumaciones con estremecimientos de placer o de agonía.

Se debe escribir en una lengua que no sea materna. Los cuatro puntos cardinales son tres: el sur y el norte. Un poema es una cosa que será.

Un poema es una cosa que nunca es, pero que debieraser.

Un poema es una cosa que nunca ha sido, que nunca podrá ser.

Huye del sublime externo, si no quieres morir aplastado por el viento.

Si yo no hiciera al menos una locura por año, me volvería loco".

Tomo mi paracaídas, y del borde de mi estrella en marcha me lanzo a la atmósfera del último suspiro. 
Ruedo interminablemente sobre las rocas de los sueños, ruedo entre las nubes de la muerte.

Encuentro a la Virgen sentada en una rosa, y me dice:

Mira mis manos: son transparentes como las bombillas eléctricas. ¿Ves los filamentos de donde corre la sangre de mi luz intacta?

Mira mi aureola. Tiene algunas saltaduras, lo que prueba mi ancianidad.

Soy la Virgen, la Virgen sin mancha de tinta humana, la única que no lo sea a medias, y soy la capitana de las otras once mil que estaban en verdad demasiado restauradas.

Hablo una lengua que llena los corazones según la ley de las nubes comunicantes.

Digo siempre adiós, y me quedo.

Ámame, hijo mío, pues adoro tu poesía y te enseñaré proezas aéreas.

Tengo tanta necesidad de ternura, besa mis cabeIlos, los he lavado esta mañana en las nubes del alba y ahora quiero dormirme sobre el colchón de la neblina intermitente.

Mis miradas son un alambre en el horizonte para el descanso de las golondrinas.

Ámame".

Me puse de rodillas en el espacio circular y la Virgen se elevó y vino a sentarse en mi paracaídas.

Me dormí y recité entonces mis más hermosos poemas.

Las llamas de mi poesía secaron los cabellos de la Virgen, que me dijo gracias y se alejó, sentada sobre su rosa blanda.

Y heme aquí, solo, como el pequeño huérfano de los naufragios anónimos.

Ah, qué hermoso..., qué hermoso.

Veo las montañas, los ríos, las selvas, el mar, los barcos, las flores y los caracoles.

Veo la noche y el día y el eje en que se juntan.

Ah, ah, soy Altazor, el gran poeta, sin caballo que coma alpiste, ni caliente su garganta con claro de luna, sino con mi pequeño paracaídas como un quitasol sobre los planetas.

De cada gota del sudor de mi frente hice nacer astros, que os dejo la tarea de bautizar como a botellas de vino.
Lo veo todo, tengo mi cerebro forjado en lenguas de profeta.

La montaña es el suspiro de Dios, ascendiendo en termómetro hinchado hasta tocar los pies de la amada.

Aquél que todo lo ha visto, que conoce todos los secretos sin ser Walt Whitman, pues jamás he tenido una barba blanca como las bellas enfermeras y los arroyos helados.

Aquél que oye durante la noche los martillos de los monederos falsos, que son solamente astrónomos activos.

Aquél que bebe el vaso caliente de la sabiduría después del diluvio obedeciendo a las palomas y que conoce la ruta de la fatiga, la estela hirviente que dejan los barcos.

Aquél que conoce los almacenes de recuerdos y de bellas estaciones olvidadas.

Él, el pastor de aeroplanos, el conductor de las noches extraviadas y de los ponientes amaestrados hacia los polos únicos.

Su queja es semejante a una red parpadeante de aerolitos sin testigo.

El día se levanta en su corazón y él baja los párpados para hacer la noche del reposo agrícola.

Lava sus manos en la mirada de Dios, y peina su cabellera como la luz y la cosecha de esas flacas espigas de la lluvia satisfecha.

Los gritos se alejan como un rebaño sobre las lomas cuando las estrellas duermen después de una noche de trabajo continuo.

El hermoso cazador frente al bebedero celeste para los pájaros sin corazón.

Sé triste tal cual las gacelas ante el infinito y los meteoros, tal cual los desiertos sin mirajes.

Hasta la llegada de una boca hinchada de besos para la vendimia del destierro.

Sé triste, pues ella te espera en un rincón de este año que pasa.

Está quizá al extremo de tu canción próxima y será bella como la cascada en libertad y rica como la línea ecuatorial.

Sé triste, más triste que la rosa, la bella jaula de nuestras miradas y de las abejas sin experiencia. 
La vida es un viaje en paracaídas y no lo que tú quieres creer.

Vamos cayendo, cayendo de nuestro cenit a nuestro nadir y dejamos el aire manchado e sangre para que se envenenen los que vengan mañana a respirarlo.

Adentro de ti mismo, fuera de ti mismo, caerás del cenit al nadir porque ése es tu destino, tu miserable destino. Y mientras de más alto caigas, más alto será el rebote, más larga tu duración en la memoria de la piedra.

Hemos saltado del vientre de nuestra madre o del borde de una estrella y vamos cayendo.

Ah mi paracaídas, la única rosa perfumada de la atmósfera, la rosa de la muerte, despeñada entre los astros de la muerte.

¿Habéis oído? Ese es el ruido siniestro de los pechos cerrados.
Abre la puerta de tu alma y sal a respirar al lado afuera. Puedes abrir con un suspiro la puerta que haya cerrado el huracán.

Hombre, he ahí tu paracaídas maravilloso como el vértigo.

Poeta, he ahí tu paracaídas, maravilloso como el imán del abismo.

Mago, he ahí tu paracaídas que una palabra tuya puede convertir en un parasubidas maravilloso como el relámpago que quisiera cegar al creador.

¿Qué esperas?

Mas he ahí el secreto del Tenebroso que olvidó sonreír. Y el paracaídas aguarda amarrado a la puerta como el caballo de la fuga interminable. 